\title{
Use of Intravenous Ketorolac as Postoperative Analgesic in Neonates: A Prospective Study in Chittagong, Bangladesh
}

Mosammat Kohinoor Parveen ${ }^{1 *}$

Selim Md Jahangir'

Mahmudul Haque ${ }^{2}$

Md Mahabubul Islam'

Rebecca Chowdhury

Jannatul Ferdous ${ }^{3}$

Tahmina Banu ${ }^{4}$

'Department of Pharmacology \& Therapeutics Chittagong Medical College

Chittagong, Bangladesh.

${ }^{2}$ Department of Biochemistry Chittagong Medical College Chittagong, Bangladesh.

${ }^{3}$ Department of Pharmacology

Chattagram Maa-O-Shishu Hospital Medical College Chittagong,Bangladesh.

${ }^{4}$ Department of Pediatric Surgery Chittagong Medical College Chittagong, Bangladesh.
*Correspondence to:

\section{Dr. Mosammat Kohinoor Parveen} Lecturer

Department of Pharmacology \& Therapeutics Chittagong Medical College

Chittagong, Bangladesh.

Mobile: +8801716319648

E-mail:kohinoor_parveen@yahoo.com

\begin{abstract}
Introduction: Painful exposures have the potential for deleterious consequences upon neonates. Although Opioids and NSAIDs play important role in postoperative pain control, those are associated with side effects. We have studied use of ketorolac as postoperative analgesic in Bangladeshi neonates. Methods: This prospective study was undertaken in the Department of Pharmacology \& Therapeutics and Department of Pediatric Surgery, Chittagong Medical College, Chittagong, Bangladesh from July 2013 to June 2014. All postoperative neonates received either ketorolac intravenously or acetaminophen per rectally every $8 \mathrm{hrs}$ for $72 \mathrm{hrs}$. Pain was assessed every 8 hours and as-needed basis by CRIES scale. Results: Out of 60 patients, 30 patients were in Ketorolac group and 30 in Acetaminophen group. Pain score was significantly low in Ketorolac group. However, heart rate, respiratory rate and temperature did not change much in either group. Four patients had unusual bleeding tendency in Ketorolac group and bleeding time in this group was significantly low on 1st postoperative day. Serum creatinine showed no significant change in either group. Two patients in each group developed edema. One patient in each group expired due to sepsis. Conclusions: Ketorolac has better analgesic efficacy than acetaminophen as postoperative analgesic in neonates, although associated with bleeding tendency.
\end{abstract}

Key words : Ketorolac; Neonates; NSAID; Acetaminophen.

\section{INTRODUCTION}

Tissue injury, which occurs during all forms of surgery, elicits profound physiologic responses. The more marked these responses to surgery, the greater the morbidities and mortality ${ }^{1}$. Pain is an inevitable consequence of surgery at every age group. Pain is of particular importance in the neonate because of the evidence of improved clinical outcomes, including decreased mortality, when adequate pain control is achieved ${ }^{2}$.

There has been a myth that the newborn has no sensation, emotional affect, or ability to feel pain or pleasure. But the fact is newborn babies experience discomfort, pain, and shock in the same way adults do, and have the same range of emotions as adults ${ }^{3}$.

The newborn period is a time of rapid brain development and therefore makes babies very vulnerable ${ }^{4}$. When and how infants begin to discriminate noxious from innocuous stimuli is a fundamental question in neuroscience ${ }^{5}$.

Recent studies of developing brain networks have emphasized the importance of transient spontaneous and evoked neuronal bursting activity in the formation of functional circuits ${ }^{6-7}$. The results suggest that specific neural circuits necessary for discrimination between touch and nociception emerge from 35-37 weeks gestation in the human brain ${ }^{8-9}$. 
Brummelte et al. (2012) demonstrated effects on subcortical structures in the brain, suggesting that repeated early procedural pain may be linked with impaired brain development ${ }^{10}$. Therefore procedures carried out during this period may effect the neurological development of their early life ${ }^{11}$.

Prior to manage postoperative pain one needs to assess it and there are several tools e.g. The Children's Hospital of Eastern Ontario Pain Scale (CHEOPS) the Objective Pain Scale (OPS) the COMFORT scale ${ }^{12}$. A number of pain assessment tools have been develeped to help nurses address the specific needs of neonates on pain. However, due to a baby's inability to selfreport there is no recognized gold standard for infant pain assessment, unlike that which exists for older children ${ }^{13}$. The alternative therefore involves physiological and behavioral indicators of pain, making assessing pain in newborns very challenging for nurses.

CRIES may also be useful to assess the pain of neonates postoperatively ${ }^{14}$. This scale analyzes 5 variables (1) Crying, (2) Requirement of increased oxygen administration (3) Increased vital signs (4) Expression and (5) Sleeplessness. Each variable is scored 0,1 , or 2 . This instrument has demonstrated validity, reliability, user friendliness, and acceptance as a postoperative pain assessment tool among neonatal intensive care nurses. So we opted to use this tool for pain assessment in postoperative neonates.

Acetaminophen is used extensively for relief of mild to moderate pain after minor surgery, has a broad margin of safety in infancy, and is metabolized and excreted efficiently by newborns ${ }^{15}$. However, the optimum route of administration is unclear. The recommended dose for per rectal paracetamol in neonates is $20 \mathrm{mg} / \mathrm{kg} / \mathrm{dose}$ up to 4 doses a day ${ }^{16}$.

Opioids provide early postoperative pain relief in children; however can produce respiratory depression ${ }^{17}$. Nonsteroidal Anti-Inflammatory Drugs (NSAID) have been used for postoperative pain. But most of the drugs in this group have a 'ceiling' effect in respect to analgesia.

Overall analgesic efficacy of intravenous acetaminophen and ketorolac were similar in adults. Patients receiving ketorolac had lower pain scores than those receiving acetaminophen between 45 and 75 min postoperatively and lower occurrence of nausea was experienced in the ketorolac group ${ }^{18}$. There are very few studies with use of intravenous ketorolac for neonatal analgesia $^{19}$. Intravenous paracetamol is yet to be used in children and neonates of Bangladesh. So we are undertaking this study to see if intravenous Ketorolac is safe and effective and whether it is more potent than paracetamol in alleviating postoperative pain in neonates after major surgeries.

General objective of this study was to find out the efficacy and safety of the IV ketorolac in postoperative pain management of neonates and specific objectives were:

1. To compare the efficacy of ketorolac in relation with acetaminophen

2. To evaluate the safety profile of ketorolac

\section{MATERIALS \& METHODS}

It was a randomized controlled trial (Single blind) and was conducted in the Department of Pharmacology \& Therapeutics and Department of Pediatric Surgery, Chittagong Medical College, Chittagong from 1, July 2013 to 30, June 2014. Neonates (Aged 0-28 days) undergoing laparotomy in the Department of Pediatric Surgery, Chittagong Medical College Hospital (CMCH) Chittagong, Bangladesh.

\section{Inclusion Criteria}

1. Neonates gestational age $>37$ weeks and less than or equal to 28 days of age.

2. Neonates who underwent a laparotomy.

\section{Exclusion Criteria}

1. Low birth weight and/or gestational age $<37$ weeks.

2. Known renal disease/Dysplastic kidneys and/or Serum Creatinine $>0.9 \mathrm{mg} / \mathrm{dl}$.

3. Patients who are currently receiving other potentially renal toxic drugs or drugs that may interfere with hemostatic pathways as part of their clinical care (Including but not limited to furosemide, vancomycin, gentamicin).

4. Patients with necrotizing enterocolitis, GI bleeding (Hematemesis and /or Melaena) ongoing disseminated intravascular coagulation or history of intraventricular hemorrhage, and patients with established sepsis.

5. Patients with a hemoglobin value $<10 \mathrm{~g} / \mathrm{dL}$, Platelet count $<$ 50,000

Clinical history questionnaire, thorough physical examination and relevant investigations were recorded in details in all cases. Parents and/or attendants of the patients were informed about the treatment options and written witnessed consent was taken. If the patient fulfilled the entry criteria then a unique ID number was allocated and this was to be appearing on all records and investigative tools. Patients were divided into 2 groups (Intravenous ketorolac - Ketorolac group and Per-rectal acetaminophen - Acetaminophen group).

Technique: When the patient came to the ward from postoperative recovery, pain was assessed according to CRIES scale and ketorolac or acetaminophen was given. Neonates received acetaminophen $20 \mathrm{mg} / \mathrm{kg}$ per rectally every $8 \mathrm{hrs}$ for $72 \mathrm{hrs}$ or ketorolac $0.5 \mathrm{mg} / \mathrm{kg}$ intravenously every $8 \mathrm{hrs}$ for $72 \mathrm{hrs}$. The postoperative management was unchanged and at the discretion of the attending surgeon, as appropriate for the surgical procedure. The patients were followed for 5 days or 48 hrs from the end of ketorolac therapy for primary and secondary endpoints.

Efficacy and Safety Evaluation: Efficacy was evaluated by measuring pain scale, monitoring heart rate, respiratory rate, passage of urine and feces. Fontanelle bulge was also checked which indicated that the baby was feeling pain as well as an indication of fluid retention also. Safety of the medicine was evaluated by clinical follow up (together with any incidence of 
hypersensitivity reactions (Urticaria, wheezing, or both), bleeding from umbilicus, gastrointestinal bleeding, renal dysfunction, or significant postoperative bleeding from woundsite) and biochemical test like serum creatinine, bleeding time and clotting time. Edema was also checked and recorded as indication of fluid retention and/or sepsis. All data that were collected in individual data collection sheet and the necessary investigation results were collected and recorded in an attached data collection sheet.

Data was processed and analyzed by using computer based software Statistical Package for Social Science (SPSS-18). Different statistical methods like 'Chi squared test' and ' $t$ test' were applied as per nature of the variables. $\mathrm{P}$ value considered as statistically significant when it is less than 0.05. This research work was approved by the Ethical Review Committee (ERC) of Chittagong Medical College, Chittagong.

\section{RESULTS}

Among 60 patients 41 were males and in Acetaminophen group, majority ( $>80 \%$ ) were males). Mean age of both groups were matched $(\mathrm{P}>0.05)$, weight and gestational age also matched $(\mathrm{p}>0.05)[$ Table 1]. CRIES score was found significantly low in ketorolac group patients than acetaminophen group on all postoperative days $(\mathrm{P}<0.05)$ indicating better analgesic effects in Ketorolac group (Table 2 and Figure 1). No significant change of heart rate, respiratory rate or temperature was found among both groups in different Post Operative Days (POD) Bowel was moved in 6 patients in ketorolac group and 3 patients in acetaminophen group on $1^{\text {st }}$ postoperative day (POD) on second POD it was more in acetaminophen group. In ketorolac group, 4 patients had unusual bleeding tendency e.g. wound site/umbilical bleeding on day 1, whereas there was no bleeding tendency in acetaminophen group patients (Table 3). Bleeding time was found significantly low on $1^{\text {st }}$ post operative day in ketorolac group than acetaminophen group $(p<0.05)$ but it became near equal in subsequent follow up (Table 4). No significant change of clotting time was found on different postoperative days in both groups (Table 5). No significant change of serum creatinine was found on different postoperative days (Table 6). In ketorolac group, one patient developed edema on $1^{\text {st }}$ POD, another on $3^{\text {rd }}$ POD and in acetaminophen group, 2 patients developed edema on $1^{\text {st }}$ POD. During evaluation of fontanelle in four postoperative days (POD) no patients were found to have bulged fontanelle in either group. One patient in ketorolac group expired on $3^{\text {rd }}$ postoperative day and one took discharge on risk bond on $4^{\text {th }} \mathrm{POD}$, one patient in acetaminophen group expired on $4^{\text {th }}$ POD.
Table 1: Demographic data

\begin{tabular}{lccc} 
Baseline findings & $\begin{array}{c}\text { Ketorolac } \\
\text { group } \\
(\mathbf{n}=\mathbf{3 0}) \\
\text { Mean } \pm \text { SEM }\end{array}$ & $\begin{array}{c}\text { Acetaminophen } \\
\text { group } \\
(\mathbf{n}=\mathbf{3 0})\end{array}$ & P value \\
Mean \pm SEM & \\
\hline Age (day) & $13.67 \pm 1.89$ & $12.53 \pm 1.56$ & 0.93 \\
Weight in Kg & $2.814 \pm 0.081$ & $2.677 \pm 0.054$ & 0.23 \\
Gestational age (weeks) & $38.87 \pm .229$ & $38.57 \pm .243$ & 0.28
\end{tabular}

Data were presented as Mean \pm SEM, Data were analyzed using Student's Independent sample ' $\mathrm{t}$ ' test., $\mathrm{P}<0.05$ is considered significant.

Table 2 : CRIES score during first four postoperative days.

\begin{tabular}{llllc}
$\begin{array}{l}\text { CRIES } \\
\text { score }\end{array}$ & $\begin{array}{l}\text { Ketorolac } \\
\text { group } \\
(\mathbf{n}=\mathbf{3 0})\end{array}$ & $\begin{array}{l}\text { Acetaminophen } \\
\text { group } \\
(\mathbf{n = 3 0})\end{array}$ & P value & Comments \\
Day 1 & $2.80 \pm 0.162$ & $3.03 \pm 0.176$ & 0.011 & $\mathrm{~S}$ \\
Day 2 & $1.80 \pm 0.188$ & $2.20 \pm .0 .237$ & 0.023 & $\mathrm{~S}$ \\
Day 3 & $0.57 \pm 0.164$ & $1.43 \pm 0.177$ & 0.014 & $\mathrm{~S}$ \\
Day 4 & $0.40 \pm 0.113$ & $0.33 \pm 0.130$ & 0.07 & $\mathrm{NS}$ \\
\hline
\end{tabular}

Data were presented as Mean \pm SEM, Student $t$ test was done to measure the significance of difference between two groups. $\mathrm{P}<0.05$ is considered significant. (S- Significant, NS- Not significant). There is no difference in day 4 when the drug was withdrawn but difference was observed in other days.

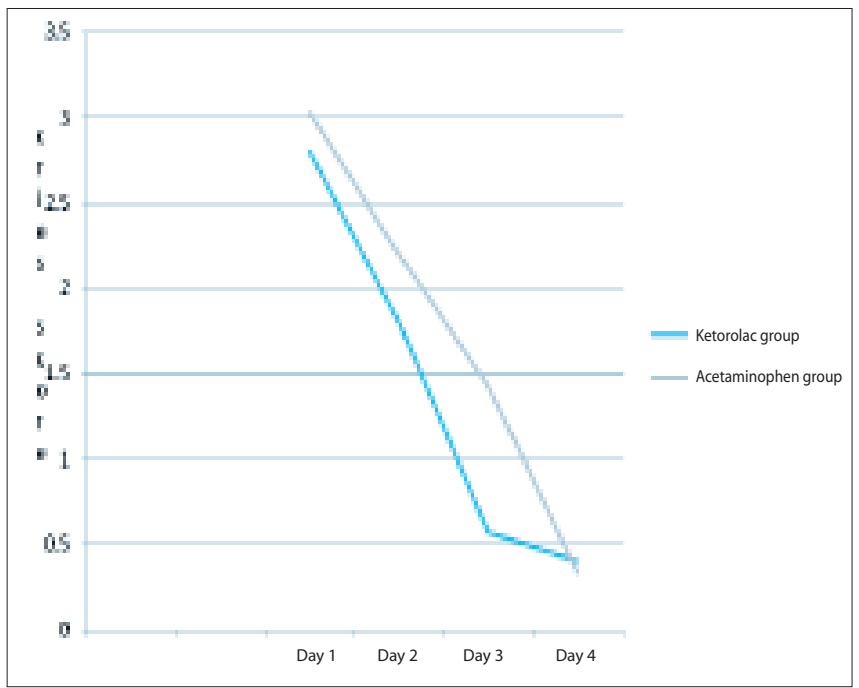

Figure 1 : CRIES score on first four postoperative days

Comparative line diagram of CRIES score of ketorolac and acetaminophen groups, showing the tendency of CRIES score values for ketorolac group and acetaminophen group touching the baseline. ketorolac group shows quicker response. 
Table 3 : Bleeding tendency during first four postoperative days

\begin{tabular}{|c|c|c|c|c|c|c|}
\hline \multirow[t]{2}{*}{$\begin{array}{l}\text { Study } \\
\text { Group }\end{array}$} & \multicolumn{2}{|c|}{$\begin{array}{l}\text { Ketorolac } \\
\text { group } \\
\mathbf{n}=\mathbf{3 0}\end{array}$} & \multicolumn{2}{|c|}{$\begin{array}{l}\text { Acetaminophen } \\
\begin{array}{l}\text { group } \\
\mathbf{n}=\mathbf{3 0}\end{array}\end{array}$} & \multirow[t]{2}{*}{$P$ value } & \multirow[t]{2}{*}{ Comments } \\
\hline & Absent & Present & Absent & Present & & \\
\hline Day 1 & 26 & 4 & 30 & 0 & 0.03 & S \\
\hline Day 2 & 30 & 0 & 30 & 0 & & \\
\hline Day 3 & 29 & 1 & 30 & 0 & 0.98 & NS \\
\hline Day 4 & 28 & 0 & 29 & 0 & & \\
\hline
\end{tabular}

Chi-square test was done to measure the significance of difference between two groups. $\mathrm{P}<0.05$ is considered significant. S- Significant, NS- Not significant. Table 3 showing bleeding tendency on first four postoperative days where at 1 (4 patients) and 3 (1 patient) in ketorolac group there were history of bleeding but none was found in acetaminophen group. Bleeding was minimal. It was just oozing from surgical woundsite or umbilicus. It required no extra measures to stop. Rather stopped spontaneously on subsequent days.

Table 4 : Bleeding time (Dukes methods) values during postoperative period (minutes)

\begin{tabular}{ccccc}
$\begin{array}{l}\text { Bleeding } \\
\text { time (Dukes } \\
\text { method) }\end{array}$ & $\begin{array}{c}\text { Ketorolac } \\
\text { group } \\
(\mathrm{n}=\mathbf{3 0}) \\
\text { Mean } \pm \text { SEM }\end{array}$ & $\begin{array}{c}\text { Acetaminophen } \\
\text { group } \\
(\mathrm{n}=\mathbf{3 0})\end{array}$ & P value & Comments \\
Mean \pm SEM & & \\
\hline Day 1 & $3.183 \pm 0.167$ & $4.153 \pm 0.230$ & 0.02 & $\mathrm{~S}$ \\
Day 2 & $3.408 \pm 0.175$ & $3.742 \pm 0.169$ & 0.47 & NS \\
Day 3 & $3.642 \pm 0.201$ & $4.052 \pm 0.249$ & 0.14 & NS \\
Day 4 & $3.713 \pm 1.683$ & $3.303 \pm 0.487$ & 0.88 & NS \\
\hline
\end{tabular}

Data were presented as Mean \pm SEM, Student's t- test was done to measure the significance of difference between two groups, $\mathrm{P}<0.05$ is considered significant. S- Significant, NSNot significant. Table 4 showing bleeding time was within normal range but during comparison with both group at day 1 it was found significant. Though they are in normal range $(1-8$ minutes in Dukes method) but $\mathrm{p}$ values are significant in day 1.

Table 5 : Clotting time (Ivy's methods) values (Minutes)

\begin{tabular}{lcccc}
$\begin{array}{l}\text { Clotting } \\
\text { time }\end{array}$ & $\begin{array}{c}\text { Ketorolac } \\
\text { group } \\
(\mathrm{n}=30) \\
\text { Mean } \pm \text { SEM }\end{array}$ & $\begin{array}{c}\text { Acetaminophen } \\
\text { group } \\
(\mathrm{n}=30) \\
\text { Mean } \pm \text { SEM }\end{array}$ & P value Comments & \\
\hline Day 1 & $3.735 \pm 0.161$ & $4.193 \pm 0.144$ & 0.66 & NS \\
Day 2 & $3.693 \pm 0.129$ & $4.303 \pm .0 .158$ & 0.98 & NS \\
Day 3 & $3.643 \pm 0.194$ & $4.453 \pm 0.175$ & 0.48 & NS \\
Day 4 & $4.053 \pm 0.216$ & $4.313 \pm 0.146$ & 0.83 & NS \\
\hline
\end{tabular}

Data were presented as Mean \pm SEM, Student's 't'-test was done to measure the significance of difference between two groups. $\mathrm{P}<0.05$ is considered significance. S- Significant, NSNot significant. Table 5 showing clotting time change where nonsignificant results were found in both groups at all postoperative days i.e. within normal range (11 minutes in Ivy's method).
Table 6 : Serum creatinine changes during postoperative period $(\mathrm{mg} / \mathrm{dl})$

\begin{tabular}{lcccc}
$\begin{array}{l}\text { Serum } \\
\text { creatinine }\end{array}$ & $\begin{array}{c}\text { Ketorolac } \\
\text { group } \\
(\mathrm{n}=\mathbf{3 0}) \\
\text { Mean } \pm \text { SEM }\end{array}$ & $\begin{array}{c}\text { Acetaminophen } \\
\text { group } \\
(\mathrm{n}=\mathbf{3 0}) \\
\text { Mean } \pm \text { SEM }\end{array}$ & P value & Comments \\
Day 1 & $0.370 \pm 0.008$ & $0.369 \pm 0.011$ & 0.23 & NS \\
Day 2 & $0.443 \pm 0.011$ & $0.428 \pm .0 .010$ & 0.45 & NS \\
Day 3 & $0.443 \pm 0.024$ & $0.438 \pm 0.025$ & 0.34 & NS \\
Day 4 & $0.430 \pm 0.016$ & $0.434 \pm 0.017$ & 0.37 & NS \\
\hline
\end{tabular}

Data were presented as Mean \pm SEM, Data were analyzed using 't'-test test. $\mathrm{P}<0.05$ is considered significant. SSignificant, NS- Not significant. Table showing change of serum creatinine at different postoperative days which were found insignificant at all follow up. Normal Serum creatinine level is $0.3-1.0 \mathrm{mg} / \mathrm{dl}$.

\section{DISCUSSION}

Very few research works have been done on postoperative analgesia in our country. We could find two on the internet, one in adults and another in children. Multimodal preemptive analgesia using IV ketorolac and bupivacaine infiltration was found to be very effective to control postoperative pain in maxillofacial surgeries ${ }^{20}$. Another study has shown that high dose per-rectal paracetamol as preemptive analgesia was more effective than per-rectal Diclofenac sodium in children ${ }^{21}$. According to T Banu, (Personal communication, December 2, 2013) Pediatric surgeons in our country have been practicing per-rectal Diclofenac sodium for immediate relief of postoperative pain in children and use ibuprofen, naproxen or mefenamic acid for oral switch therapy. For postoperative analgesia in neonates, although a single dose of opioid (Pethidine) is used in some centers during anesthesia recovery (S Alam, personal communication, March 15, 2014) opiod use has not been a routine practice in our country. The reason may be the lack of adequate monitoring facility due to shortage of nurses as well as equipments (Pulse oxymeter) because respiratory depression is a well known adverse effect of opiods $^{22}$. The common practice thus in our country is to administer per-rectal acetaminophen for postoperative analgesia in neonates (M Hoque, personal communication, January 5, 2014).

Ketorolac was approved by the Food and Drug Administration (FDA) in 1989, making it the first parenteral Nonsteroidal Anti-Inflammatory Drug (NSAID) available in the United States $^{23}$. As in adults, ketorolac has been shown to provide effective postoperative pain relief in children, often decreasing opioid requirements. It is generally well tolerated, but the risk for bleeding and renal dysfunction must always be taken into consideration $^{24}$. However, minimal safety data exist regarding the use of ketorolac in neonates ${ }^{25}$. 
The present study looked into two main outcome measures: efficacy and safety of intravenous ketorolac for postoperative analgesia in neonates and were compared with similar parameters of acetaminophen. Efficacy was assessed principally by use of pain scoring (CRIES) and was found to be significantly low with ketorolac during all four postoperative days indicating better analgesic efficacy. According to Taddio et al. (2000) regarding pain relief during operation, found Facial action scores and percentage of time spent crying were significantly lower during circumcision for infants in group who took ketorolac $(\mathrm{P}<.001)^{26}$. The percentage of time spent crying was $18 \%$ and $40 \%$ for infants in groups 1 and 2 , respectively. So, in pain relief ketorolac has some better outcome than acetaminophen.

Changes in heart rate and respiratory rate and temperature during postoperative period, passage of feces and urine at usual times were also recorded. These variables could be affected by the intensity of the pain felt by the postoperative neonates. In the current study the heart rate and respiratory rate changes were not significantly different between two groups. Temperature was not significantly different between groups. Bowel was moved in maximum patients in both groups, most patients passed their urine from the beginning of the operation. There are scarcity of published materials on postoperative ketorolac use in neonates, those available are mainly on children and those available on neonates express the similar findings as in this study ${ }^{25,27}$. According to Taddio et al. (2000) both acetaminophen and ketorolac are safe drugs regarding cardiac activity, respiratory function and temperature regulation. So findings in this study are consistent with their inference ${ }^{26}$.

The safety status of intravenous ketorolac in neonates was ascertained principally on two variables: bleeding tendency and serum creatinine levels during postoperative period. Other variables include: bleeding time, clotting time, skin color changes, and development of edema and bulging of fontanelle.
Aldrink JH et al. (2011) state that neonates of less than 21 days may have increased risk for bleeding after intravenous ketorolac ${ }^{25}$. However many other studies demonstrated that intravenous ketorolac is safe to use in neonates in regard to bleeding manifestations ${ }^{27-28}$. The bleeding tendency may be transient due to temporary fall in platelet count in some patients ${ }^{29}$. In the current study, bleeding tendency was significantly higher in ketorolac group on the first postoperative day. However during subsequent days there was no significant difference between the groups. A randomized, double-blind study was done by Ceelie et al (2013) also noticed higher prevalence of bleeding tendency in postoperative day with ketorolac $^{30}$.

Although there was skepticism about use of ketorolac from the fear of renal compromise, it is now becoming analgesic of choice for use in neonates after major surgeries ${ }^{31-32}$. The serum creatinine levels in the present study did not change significantly between the groups. Development of edema could be explained by the fluid retention which can occur after NSAID use. Findings of edema in this study were transient. Change of skin color could be a manifestation of bleeding and or development of sepsis. In this study two patients one from each group had skin color change. Both these babies were later diagnosed as having developed sepsis and eventually expired.

\section{LIMITATIONS OF THE STUDY}

The study has a small sample size and lacks long term follow up. The drug level was not measured. There may be some assay related pitfalls as some were done by the different laboratories.

\section{CONCLUSIONS}

Intravenous Ketorolac has better analgesic efficacy than perrectal acetaminophen in the management of postoperative pain in neonates, although it is associated with bleeding tendency. However, study with larger series is required to come to a definite conclusion.

\section{DISCLOSURE}

All the authors declared no competing interest. 


\section{REFERENCES}

1. Barker DP, Rutter N. Stress, severity of illness, and outcome in ventilated preterm infants. Arch Dis Child Fetal Neonatal Ed. 1996; 75: F187- F190.

2. Anand KJS and the International Evidence-Based Group for Neonatal Pain. Consensus Statement for the Prevention and Management of Pain in the Newborn. Arch Pediatr Adolesc Med. 2001; 155:173-180.

3. Myth: The Newborn Has no Sensation, Emotional Affect, or Ability to Feel Pain or Pleasure. Retrieved May 23, 2010, from http://www.thewellspring.com > The First Year.

4. Kostovic I and Judas M. The development of the subplate and thalamocortical connections in the human foetal brain. Acta Pediatr. 2010; 99: 1119-1127.

5. Anand KJ, Aranda JV, Berde CB, Buckman S, Capparelli EV, Carlo W, Hummel P, Johnston CC, Lantos J, Tutag-Lehr V et al. Summary proceedings from the neonatal pain-control group', Pediatrics. 2006; 117: S9-S22.

6. Blankenship AG, and Feller MB. Mechanisms underlying spontaneous patterned activity in developing neural circuits. Nat Rev Neurosc. 2010; 11: 18-29.

7. Khazipov R, and Luhmann HJ. Early patterns of electrical activity in the developing cerebral cortex of humans and rodents. Trends Neurosci. 2006; 29: 414-418.

8. Fabrizi L, Slater R, Worley A, Meek J, Boyd S, Olhede S, Fitzgerald M. A Shift in Sensory Processing that Enables the Developing Human Brain to Discriminate Touch from Pain. Curr Biol. 2011; 21: 1552-1558.

9. Slater R, Worley A, Fabrizi L, Roberts S, Meek J, Boyd S, and Fitzgerald M. Evoked potentials generated by noxious stimulation in the human infant brain. Eur J Pain. 2010; 14: 321-326.

10. Brummelte S, Grunau RE, Chau V, Poskitt KJ, Brant R, Vinall J, Gover A, Synnes AR and Mille, SP. Procedural pain and brain development in premature newborns. American Neurological Association. 2012; 71: 385-396.

11. Fabrizi L and Slater R. Exploring the relationship of pain and development in the neonatal intensive care unit. Pain. 2012; 153: 1340-1341.

12. Burt N, Havidich J. Perioperative Pain Management in Newborns. Anestesia Pediatrica e Neonatale/Italian Internet Journal of Pediatric and Neonatal Anesthesia. 2004; 2 (2): 34-45 URL: http://www.anestesiapediatrica.it.

13. Warnock F and Lander J. Foundations of knowledge about neonatal pain. J Pain Symptom Manage 2004; 27 (2): 170-179.

14. Krechel SW and Bildner J. CRIES: a new neonatal postoperative pain measurement score: initial testing of validity and reliability. Pediatr Anesth. 1995; 5 (1): 53-61.

15. Howard CR, Howard FM, Weitzman ML. Acetaminophen analgesia in neonatal circumcision: the effect on pain. Pediatrics. 1994; 93: 641-646.

16. Anderson BJ, Allegaert K. Intravenous neonatal paracetamol dosing: the magic of 10 days. Pediatr Anesth. 2009; 19 (4): 289-295.

17. Gill AM, Cousins A, Nunn AJ, Choonara IA. Opiate-induced respiratory depression in pediatric patients. Ann Pharmacother. 1996; 30:125-129.

18. Anand A, Sprenkera CJ, Karlnoskia R, Normanb J, Miladinovicc B, Wilburnd B, Southalld RA, Mangara, D, Camporesia, E. Intravenous acetaminophen vs. ketorolac for postoperative analgesia after ambulatory parathyroidectomy. Scand J Pain. 2013; 4 (4): 249-253.

19. Houck, CS, Wilder, RT, McDermott, JS, Sethna, NF, Berde, CB. Safety of intravenous ketorolac therapy in children and cost savings with a unit dosing system', J Pediatr. 1996; 129 (2): 292-296.

20. Khatun S, Molla MR, Akhteruzzaman AKM, Rahman MS. Effectiveness of multimodal preemptive analgesic therapy in maxillofacial surgery. Bangladesh J Physiol Pharmacol. 2008; 24 (1\&2): 17-23.

21. Yasmin R, Akhteruzzaman AKM, Sarker PC, Ahmed N, Kundu RK, Iqbal KM. Preemptive analgesia for postoperative pain relief in children- role of paracetamol. J Bangladesh Soc Anaesthesiol. 2005; 18 (1 \& 2): 9-16.

22. Papacci P, De Francisci G, Iacobucci T, Giannantonio C, De Carolis MP, Zecca E, Romagnoli C. Use of intravenous ketorolac in the neonate and premature babies. Pediatr Anesth. 2004; 14 (6): 487-492.

23. Ketorolac. Drug Facts and Comparisons 4.0. Efacts [online]. 2011. Available from Wolters Kluwer Health, Inc. (accessed 7/8/11).

24. Lynn AM, Bradford H, Kantor ED, Andrew M, Vicini P, Anderson GD. Ketorolac tromethamine: stereo-specific pharmacokinetics and single-dose use in postoperative infants aged 2-6 months. Pediatr Anesth. 2011; 21 (3): 325-334.

25. Aldrink JH, Ma M, Wang W, Caniano DA, Wispe J, Puthoff T. Safety of ketorolac in surgical neonates and infants 0 to 3 months old. J Pediatr Surg. 2011; 46 (6): 1081-1085.

26. Taddio A, Pollock N, Gilbert-MacLeod C, Ohlsson K; Koren G. Combined Analgesia and Local Anesthesia to Minimize Pain During Circumcision. Arch Pediatr Adolesc Med. 2000; 154: 620-623.

27. Gupta A, Daggett C, Drant S, Rivero N, Lewis A. Prospective randomized trial of ketorolac after congenital heart surgery. J Cardiothorac Vasc Anesth. 2004; 18: 454-457.

28. Moffett BS, Wann TI, Carberry KE, Mott AR. Safety of ketorolac in neonates and infants after cardiac surgery. Paediatric Anaesthesia. 2006; 16 (4): 424-428.

29. Rusy LM, Houck CS, Sullivan LJ, Ohlms LA, Jones DT, McGill TJ, Berde CB. A double-blind evaluation of ketorolac tromethamine versus acetaminophen in pediatric tonsillectomy: analgesia and bleeding. Anesth \& Analg. 1995; 80 (2): 226-229.

30. Ceelie I, de Wildt SN, van Dijk M. Effect of Intravenous Paracetamol on Postoperative Morphine Requirements in Neonates and Infants Undergoing Major Noncardiac Surgery: A Randomized Controlled Trial. JAMA. 2013; 309:149-154.

31. Myles PS, Power I. Does ketorolac cause postoperative renal failure: how do we assess the evidence? Br J Anaesth. 1998; 80: 420-421.

32. Burd RS, Tobias JD. Ketorolac for pain management after abdominal surgical procedures in infants. South Med J. 2002; 95: 331-333. 